\title{
Water in Sport: Yarra Ranges Council
}

\section{Introduction}

During 2018-2020, Yarra Ranges council partnered with VicHealth to improve access to water and create healthy drink environments in 6 sports and recreation facilities.

The facilities we worked with included:

$\rightarrow$ Belgrave Outdoor Heated Pool

$\rightarrow$ Healesville Outdoor Pool

$\rightarrow$ Kilsyth Centenary Pool

$\rightarrow$ Lilydale Outdoor Pool

$\rightarrow$ Monbulk Aquatic Centre

$\rightarrow$ Yarra Centre

\section{Objectives}

$\rightarrow$ Increase the promotion and supply of water and reduce the availability and supply of sugary drinks in our community sports and recreation facilities. (>50\% GREEN drinks like water and $<20 \%$ RED sugary drinks)

$\rightarrow$ Strengthen council policies and practices to enable longerterm changes to healthy drinks environments across council-owned sport and recreation facilities.
The Healthy Choices: food and drink classification guide uses a traffic light system to classify foods and drinks as:

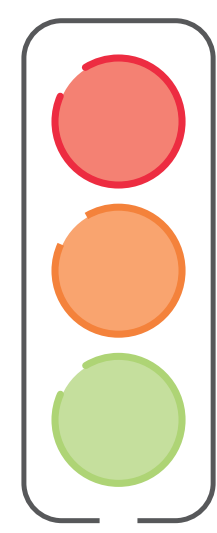

RED: Limit intake

AMBER: Choose carefully

GREEN: Best choice
Why

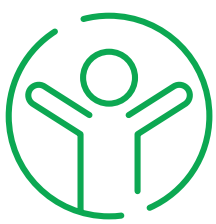

Yarra Ranges council has a

commitment to supporting the health and wellbeing of our community.
The environments in which we live, work, learn, and play are key drivers of the types of food and drink we consume. Local governments can play a key role in implementing policies and practices to improve local food and drink environments.
There is community support and expectation for healthy food and drinks $-75 \%$ of customers surveyed from all Water in Sport councils believed that sport and recreation facilities should promote healthy eating. 


\section{Outcomes}

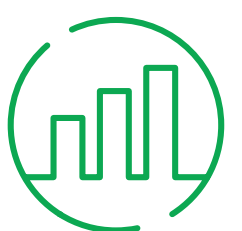

Overall, availability of 'GREEN' drinks increased from $37 \%$ to $68 \%$ of all drinks and 'RED' drinks decreased from $48 \%$ to $19 \%$ of all drinks.

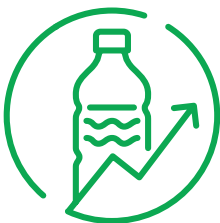

Monbulk Aquatic Centre sales of

'GREEN' drinks increased $19 \%$ between June 2018 and February 2020. There was no change in total drinks revenue.

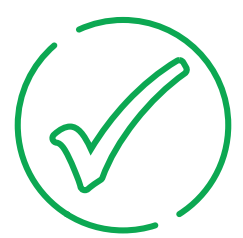

All facilities implemented changes to improve the availability of 'GREEN' drinks and reduce the availability of 'RED' drinks in their retail outlets.

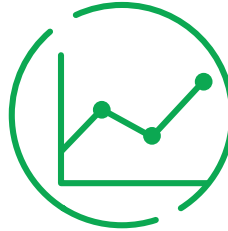

Yarra Centre sales of 'GREEN' drinks increased $15 \%$ and sales of 'RED' drinks decreased $11 \%$ between June 2018 and February 2020. There was no change in total drinks revenue.

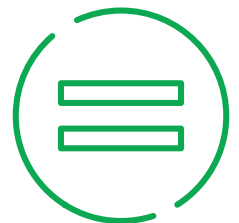

Kilsyth Centenary Pool, Healesville Outdoor Pool and Lilydale Outdoor Pool had no change in total drinks revenue between April 2018 and February 2020.

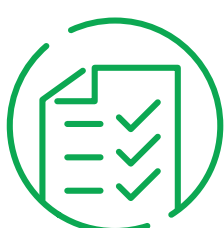

Yarra Ranges drafted a catering policy to support healthy food and drink catering at council funded meetings, events and functions.

\section{Recommendations for creating healthy food retail environments in your community}

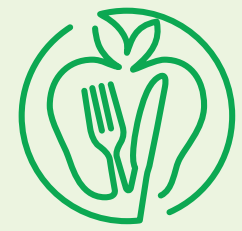

Use the VicHealth toolkit for creating healthy food and drink environments in community

food retail outlets.

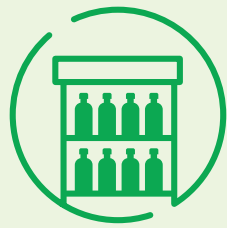

Start by trialing a small 'quick win' which is easy to implement and unlikely to cause revenue loss, such as rearranging the fridge to put 'GREEN' drinks at eye-level.

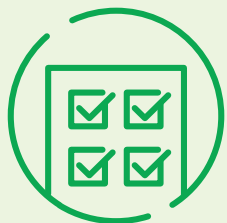

Develop healthy food environment policies and procedures for councils and facilities.

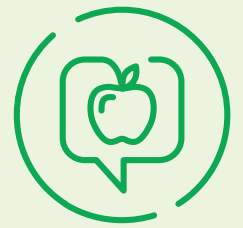

Contact the Healthy Eating Advisory Service for practical implementation support.
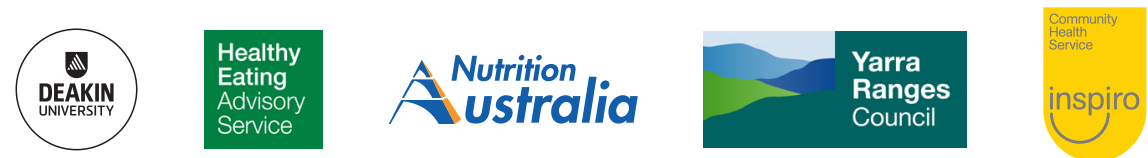